\title{
OPINION
}

\section{Healthy migration: A public health and development imperative for south(ern) Africa}

\begin{abstract}
J Vearey
Jo Vearey, PhD, is a senior researcher with the African Centre for Migration \& Society, School of Social Sciences, University of the Witwatersrand, Johannesburg, South Africa. With a commitment to social justice and the development of pro-poor policy responses, Jo's current research explores international, regional, national and local responses to migration, health, and urban vulnerabilities.
\end{abstract}

Corresponding author: J Vearey (jovearey@gmail.com)

\begin{abstract}
South Africa (SA), like the rest of the Southern African Development Community, has a high prevalence of communicable diseases, an increasing non-communicable disease burden, and diverse internal and cross-border population movements. Healthy migration is good for development, but current prevention, testing and treatment responses within public health systems - particularly for chronic conditions fail to engage with migration. Understanding of migration is poor within sectors responsible for developing appropriate responses; negative, unsupported assumptions relating to the prevalence of cross-border migration, the spread of disease, and the burden on receiving health systems prevail. In SA, public health responses fail to address internal and cross-border mobilities, and non-nationals face challenges in accessing healthcare. Of particular concern is the lack of nationally and regionally co-ordinated strategies to ensure treatment continuity for chronic conditions. Co-ordinated, evidence-informed responses to migration, mobility and health are urgently needed. These will have developmental and public health benefits for all.
\end{abstract}

S Afr Med J 2014;104(10):663-664. DOI:10.7196/SAMJ.8569

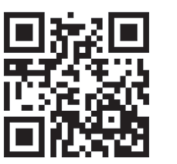

Healthy migration is good for development, but migration is rarely managed in a healthy way. ${ }^{[1,2]}$ Migration and mobility are recognised globally to be central determinants of health and as key concerns for public health programming, yet appropriate responses to population movements and health are lacking in the Southern African Development Community (SADC) region. ${ }^{[3-5]}$ Given the historical and contemporary importance of population movements in the SADC, the high communicable disease - and increasing non-communicable disease (NCD) - burden in the region, and the knowledge that healthy migration is good for development, it is surprising that health responses do not sufficiently engage with, and respond to, migration and mobility. A large body of evidence acknowledges that the relationship between migration, mobility and health in the region is complex: while the migrant labour system was clearly implicated in the early transmission and spread of syphilis, tuberculosis (TB) and HIV (especially in relation to the ongoing systems of labour migration associated with the mines in South Africa (SA)), these dynamics have changed over time, and the association between movement and the spread of communicable diseases is less clear cut today ${ }^{[4]}$ However, prevention, testing and treatment programmes for common communicable diseases and NCDs in the SADC must be continuously available for those who move, both within countries and across borders. Key concerns in 2014 relate to the (lack of) effective management of chronic conditions for those who move. This has negative implications not only on the morbidity and mortality of a highly mobile population, but also on the healthcare systems and family structures that are forced to manage the costs associated with delayed healthcare seeking.

\section{The diversity of movement}

While the majority of people who move within the SADC do so within the borders of their country of birth, a smaller - yet important - number move across national borders. Globally, just over 3\% of the world's population are estimated to be cross-border migrants; this is also observed in SA, where - despite popular assumptions to the contrary $-3.3 \%$ of the country's population are non-citizens. ${ }^{[6]}$ Migration and movement are not homogeneous processes, and those who move form heterogeneous groups; it is exactly this complexity that public health responses in the SADC must engage with and respond to. Owing to the ways in which people move and the spaces they transit or at which they arrive, migrants may reside in - or pass through spaces of vulnerability, ${ }^{[1,7,8]}$ spaces that contain a combination of social, economic and physical conditions that may increase the likelihood of exposure to, and acquisition of, a communicable disease, or of developing an NCD. The daily stressors that may be experienced in these spaces are increasingly acknowledged to affect emotional wellbeing and mental health. ${ }^{[9]}$

\section{Healthy migration?}

Within the SADC region (as is often the case globally), healthseeking is an assumed reason for movement - yet evidence suggests otherwise; the majority move in search of improved livelihood opportunities, and to do so they need to be in good health. ${ }^{[5]}$ An important phenomenon, the 'healthy migrant effect', is the common observation that recent arrivals are in better health than the local population, reflecting the positive selection of migrants - to move, an individual needs to be healthy. ${ }^{[10]}$ However, this health benefit is seen to deteriorate, sometimes rapidly, as a result of the conditions in which migrants live and work. This is particularly the case in cities, and is mostly associated with the inability of migrants - both internal and cross-border - to access positive determinants of health in the city, a phenomenon known as the urban health penalty. ${ }^{[11]}$

\section{Responding to migration and health}

When considering the development of appropriate responses to population movements and health in the SADC, it is essential that discussions do not get twisted (as they often do) into debates that 
focus solely on cross-border migrants. As indicated above, the majority who move are internal migrants (i.e. national citizens of member states), and internal mobility is recognised as placing the greatest developmental challenges on national and local governments. ${ }^{[2]}$ Despite this, the notion of 'migration' within the SADC region - including in SA - is often quickly (re)interpreted to refer exclusively to cross-border migration, leading to discussions of immigration management and border securitisation. When health is added to the equation, with unsupported assumptions relating to the health burden presumed to be presented by cross-border migrants and the communicable diseases they are assumed to spread, questions relating to whether non-citizens deserve public healthcare, and the rationing of healthcare services, prevail. As a result, population movement remains excluded from the development of improved health system responses to communicable and non-communicable diseases in the SADC, with negative public health consequences.

\section{The policy context}

In 2008, the World Health Assembly passed a Resolution on the Health of Migrants. ${ }^{[1]}$ This resolution calls on member states (including SA) to improve responses to the health of migrants. Meanwhile, in 2009, a Framework for the Control of Population Mobility and Communicable Diseases was drafted in the SADC. This calls for the development of a co-ordinated regional response to migration and health, including cross-border referral systems and financing mechanisms. However, SA is still to approve and ratify the framework. At the same time, the SADC HIV and AIDS Strategic Framework, 2009 - 2015, was finalised, highlighting the need to ensure that migrant and mobile populations are considered in regional responses to HIV. The year 2012 saw the ratification of the SADC Declaration on Tuberculosis in the Mining Sector, which clearly outlines the need for improved, co-ordinated regional responses to the migrant labour systems associated with SA mines, and HIV and TB.

\section{SA responses}

In SA, responses have mostly been restricted to discussions related to key populations (viewing migrants, particularly cross-border migrants, as such a group) and the country's HIV response. Additionally, a Migrant Health Forum (MHF) in Johannesburg (established in 2008) brings together various researchers and civil society representatives, including non-governmental, communitybased and international organisations, working on migration and health in the city. Different iterations of the MHF have, with the support of the International Organization for Migration and the Office of the Premier in Limpopo Province, been established in several districts in Limpopo.

Despite official recognition of the public health importance of ensuring timely access to health for all within legislative frameworks, non-nationals continue to face multiple, intersecting challenges when attempting to access public healthcare in SA. ${ }^{[1,5,12]}$ Key challenges exist in how frontline staff - including security guards, receptionists and data clerks - engage with and treat non-nationals. In 2014, these challenges have worsened (particularly in Gauteng Province), with increasing reports of incorrect fee classification for higher levels of care being made, and upfront payment being demanded for emergency care. This appears to be in response to guidelines and posters circulated by the provincial Department of Health which demand up-front payment for all treatment and imply the need for frontline staff to act as immigration officials. These actions are unhelpful - not only in terms of the misapplication of policy and the associated extralegal implications of denying access to care, but in the negative public health consequences for all in $\mathrm{SA}$ and the additional costs and burdens associated with delayed healthcare seeking.

\section{What is needed?}

A growing body of evidence provided by researchers, civil society and international organisations emphasises the following:

- Training on migration, mobility, health and development for all levels of staff in the Department of Health, including frontline staff, healthcare providers, facility managers, district and provincial health co-ordinators, and within the national department.

- Recognition of the importance of internal mobility within SA and other countries in the SADC region, and the development of migration-aware health systems.

- SA should lead the development of a co-ordinated regional response to migration, mobility and health.

- Effective implementation of current protective and progressive legislation relating to the right to health for non-nationals in SA.

- Correct classification of non-nationals when being means tested for co-payment for healthcare.

- Implementation of national monitoring of the correct implementation of existing legislation within health facilities.

- Health passports or regionally recognised 'road-to-health' cards for all (a form of patient-held records).

- Referral letters for internal AND cross-border migrants.

- The establishment of local migrant health forums.

1. Vearey J, Nunez, L. Migration and Health in South Africa: A Review of the Current Situation and Recommendations for Achieving the World Health Assembly Resolution on the Health of Migrants. Pretoria: International Organization for Migration, 2010.

2. Landau L, Segatti AWK. Human development impacts of migration: South Africa case study. Human Landau L, Segatti AWK. Human development impacts of migration: South Africa case study. Human
Development Research Paper Series 2009;5. http://mpra.ub.uni-muenchen.de/19182/ (accessed 18 August 2014).

3. Deane KD, Parkhurst JO, Johnston D. Linking migration, mobility and HIV. Trop Med Int Health 2010;15(12):1458-1463. [http:///x.doi.org/10.1111/j.1365-3156.2010.02647.x]

4. Lurie MN, Williams B. Migration and health in southern Africa: 100 years and still circulating. Health sychology and Behavioral Medicine: An Open-Access Journal 2014;2(1):34-40. [http://dx.doi.org/10. 1080/21642850.2013.866898]

5earey J. Learning from HIV: Exploring migration and health in South Africa. Glob Public Health 2012;7(1):58-70. [http://dx.doi.org/10.1080/17441692.2010.549494]

6. StatsSA. Census 2011: Census in Brief. Pretoria: StatsSA, 2012.
7. Crush J. Spaces of Vulnerability: Migration and HIV/AIDS in South Africa. Southern African Migration Programme Migration Policy Series No. 24, 2002.
.

Migration Programme Migration Policy Series No. 24, 2002.
8. International Organization for Migration. Migration and Health in SADC: A Review of the Literature. International Organiz
Pretoria: IOM, 2011,

9. Vearey J, Nunez L, Lakika D. Exploring the Psychosocial \& Health Rights of Forced Migrants in Vearey J, Nunez L, Lakika D. Exploring the Psychosocial \& Health Rights of Forced Migrants in
Johannesburg: The Impact of 'Daily Stressors' on the Emotional Wellbeing of Forced Migrants. Johannesburg: The Impact of 'Daily Stressors' on the Emotional Wellbeing of Forced Migrants.
Johannesburg: Centre for the Study of Violence and Reconciliation and African Centre for Migration Johannesburg: Centre for the Study of Violence and

10. Malmusi D, Borrell C, Benach J. Migration-related health inequalities: Showing the complex 10. Malmusi D, Borrell C, Benach J. Migration-related health inequalities: Showing the complex
interactions between gender, social class and place of origin. Soc Sci Med 2010;71(9):1610-1619. interactions between gender, social class and place of origin. Soc Sci Med 2010;71(9):1610-1619.
[http://dx.doi.org/10.1016/j.socscimed.2010.07.043] [http://dx.doi.org/10.1016/.socscimed.2010.07.043]

11. Vearey J. Migration, urban health and inequality in Johannesburg. In: Bastia T, ed. Migration and
Inequality. London: Routledge, 2013:121-144. 12. Vearey J. Migration, access to ART, and survivalist livelihood strategies in Johannesburg. Afr J AIDS
Res 2008; 7(3):361-374. [http://dx.doi.org/10.2989/AJAR.2008.7.3.13.660] 